\author{
경남흑돈(버크셔)에서 성장곡선을 이용한 성장형질의 추정 \\ 도 창 희 \\ 경남 첨단양돈연구소
}

\title{
Estimation of Growth Traits Using Growth Curve in Gyungnam-heugdon (Berkshire)
}

\author{
C. H. Do
}

Gyungnam Swine Research Institute

\begin{abstract}
The growth traits in swine are economically important, which are measured by gain in weight during test period or by age of days to certain weight. However, the difference in growth rate due to individual performance and also other factors occurs. The more reasonable estimation of the measurements of these traits provides the less error in genetic evaluation of pigs. The data from 1,576 heads being weighed periodically of Gyungnam-heugdon (Berkshire) were analyzed to estimate the growth curve which is used to decide average daily gain and days to $90 \mathrm{~kg}$. It may not be possible to directly compare accuracy between the conventional methods and the alternative methods. However, the alternative methods by growth curve would be superior to the conventional methods not only in theoretical background, but also in acceptability for diverse factors such as breed, sex and age. The theoretical superiority of the alternative methods comes from estimation at same age in daily gain and calculation of additional days from measuring date to days to $90 \mathrm{~kg}$ by growth curve of individual. Also this can be easily adopted in a computer system according to breed and sex.
\end{abstract}

(Key words: Growth curve, Daily gain, Days to 90kg, Estimation)

$$
\text { I. 서 론 }
$$

돼지에서 성장형질은 경제적으로 중요한 형 질이다. 이를 대표하는 형질로서 일일 평균 증 체량 또는 $90 \mathrm{~kg}$ 도달일령을 사용하여 성장속 도를 평가하여 왔다. 일일 평균 증체량과 $90 \mathrm{~kg}$ 도달일령은 성장률을 나타내는 동일한 속성을 가지고 있다. 일당증체량은 개시체중과 종료체 중간의 차이와 개시시와 종료시 간의 일수를 계산하여 측정하고 평가하여 왔으나, 효율적인
검정을 위하여 종료체중 만을 이용하여 일당증 체량을 측정하는 것이 일반화되었다. 그러나 종료체중 측정시 돼지의 연령, 품종, 성별에 따 라 성장 유형이 다르게 나타날 수 있다(조 등, 2004). 만약 다양한 성장 속도를 적절히 감안하 지 않을 경우 일당증체량과 $90 \mathrm{~kg}$ 도달일령은 돼지의 개체별 성장속도를 잘 나타내지 못할 수 있다. 미국에서는 계수화 된 추정방법 (NSIF, 2002)에 의한 250lb 도달일령을, 캐나다 는 일당증체량(CCSI, 1997)을 이용한다. 이에

Corresponding author : C. H. Do, Gyungnam Swine Research Institute Sancheong Gyungnam 666-962 Korea Tel : 82-55-970-7475 E-mail : ivando@gsnd.net 
본 연구에서는 버크셔 품종의 돼지에서 일당증 체량과 $90 \mathrm{~kg}$ 도달일령을 정확하게 보정하기 위한 방법으로 성장곡선을 추정하고 이를 이용 하는 것에 대하여 고찰하였다.

\section{․ 재료 및 방법}

2003년부터 2006년까지 경남첨단양돈연구소 에서 사육된 같은 집단의 버크셔 품종의 돼지 5,309 두의 혈통자료와 3,100 두의 검정기록을 이 용하여 연구를 수행하였다. 성장곡선 추정을 위해 생시체중, 이유체중, 검정 개시체중, 종료 체중 그리고 출하체중이 이용되었다. Gompertz (Winsor, 1932) 모형을 채택하여 비선형추정 SAS package(SAS, 2001)를 이용하여 성장곡선 을 추정하였다. 정확성을 점검하기 위하여 다 형질 derivative free REML(USDA, 2006)을 이용 유전상관과 표현형 상관을 추정하였다.

\section{III. 결과 및 고찰}

성장곡선 추정을 위해 사용된 자료의 기본 통계량은 Table 1에 제시되었다. 생시체중은 $1.43 \mathrm{~kg}$ 이었으며, $92.6 \mathrm{~kg}$ 도달하는데 약 152 일 이 걸렸다. 평균 출하체중은 $107 \mathrm{~kg}$ 정도 이었 으며, 출하일은 173 일정도 이었다. 생시부터 이
유까지 일당증체량은 $281 \mathrm{~g}$ 이었으며, 생시부터 검정개시까지 일당증체량은 $385 \mathrm{~g}$ 이다. 생시부 터 검정 종료일까지 일당증체량은 $609 \mathrm{~g}$ 이었으 며, 생시부터 출하일까지 일당증체량은 $619 \mathrm{~g}$ 이었다. 검정 개시부터 종료일까지 일당증체량 은 $784 \mathrm{~g}$ 이었다.

버크셔 품종의 특성을 살펴보기 위하여 Fig. 1과 2에서 성장곡선을 추정하였으며 Fig. 1에 성별 성장곡선이 제시되었다. 돼지의 성장곡선 은 성별에 따라 차이가 난다. 2차 성징이 나타 나기 시작하는 100 일령에서부터 성장률은 암퇘 지와 수퇘지가 달라지는데 12 개월령이 되면 버 크셔 암수의 차이는 $15 \mathrm{~kg}$ 이상이 된다. 보통 웅성 호르몬의 작용에 의하여 성장이 촉진되어 수퇘지가 성장이 빠를 것으로 기대된다. 그러 나 Fig. 1에서 보여주듯이 거세돈의 성장이 수 퇘지 보다 빠르게 나타났다. 거세돈의 성장이 빠르게 나타나는 정확한 생리적인 기작은 밝혀 지지 않았지만 140 일령 이후에는 수퇘지의 성 욕에 따른 스트레스가 거세돈 보다 성장을 느 리게 한다고 추측해 볼 수 있다. 거세돈의 육 질이 수퇘지 보다 우수하고 웅취가 없다. 더구 나 출하시 수퇘지보다 좋은 가격이 형성되고 있어 약 175 일경에 출하하는 농가로서는 수퇘 지의 거세가 소득제고 면에서 바람직하다는 것 이 실증적으로 입증되었다 할 수 있다.

Table 1. Basic statistics from the body weight for estimating the growth curve

\begin{tabular}{|c|c|c|c|c|c|c|c|}
\hline \multirow{2}{*}{ Period } & \multirow{2}{*}{ Obs. } & \multicolumn{3}{|c|}{ Days at weighing } & \multicolumn{3}{|c|}{ Body weight } \\
\hline & & Range & SD & Mean & Range & SD & Mean \\
\hline Birth & 1,576 & 1 & 0 & 1.0 & $0.7-2.5$ & 0.28 & 1.43 \\
\hline Wean & 1,576 & $17-32$ & 3.2 & 22.6 & $1.5-10.9$ & 1.60 & 6.35 \\
\hline On-test & 1,576 & $51-78$ & 3.2 & 70.5 & $6-48$ & 5.48 & 27.14 \\
\hline Off-test & 891 & $128-188$ & 12.6 & 152.0 & $56-137$ & 12.16 & 92.57 \\
\hline Test ${ }^{1)}$ & 891 & $61-118$ & 12.1 & 81.4 & $31-102$ & 11.06 & 63.83 \\
\hline Market & 434 & $152-196$ & 8.2 & 172.6 & $38-140$ & 12.23 & 106.81 \\
\hline
\end{tabular}

Test ${ }^{1)}$ represents weight gained during the test period. 


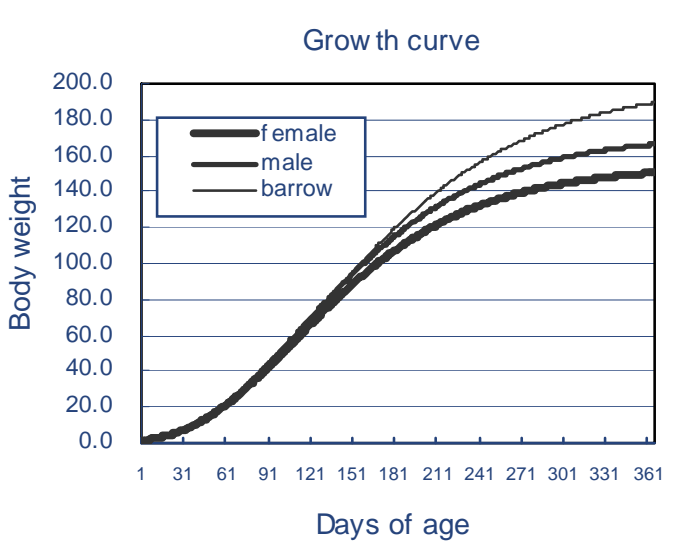

Fig. 1. Growth curves of Berkshire according to sex.

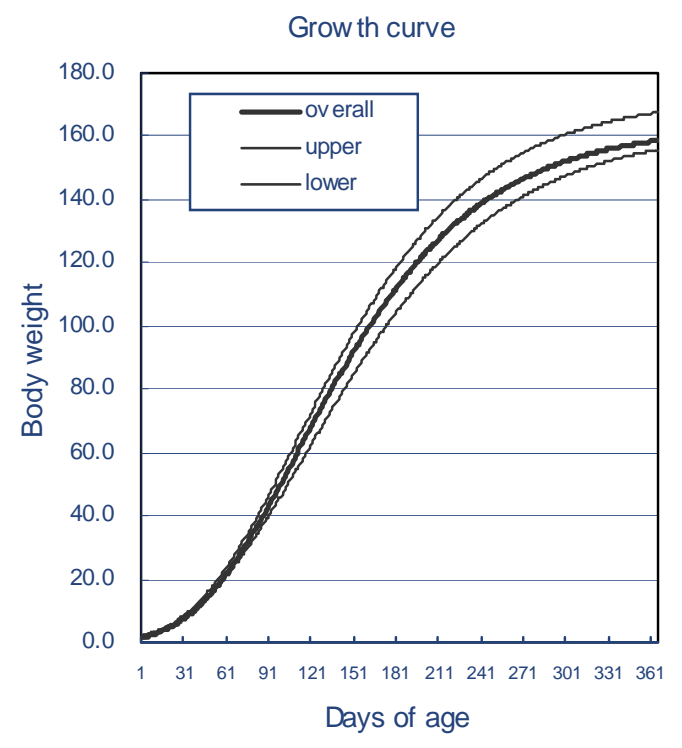

Fig. 2. Upper, lower and overall growth curve of Berkshire breed.

Fig. 2는 조숙 개체와 만숙 개체를 종료체중 과 종료일에 의해 성장곡선을 기준으로 상하 분류하여 추정하였다. 성별 차이와 조숙 만숙 의 성숙도에 의한 혼동(confounding)을 막기 위 하여 성별 성장곡선(growth curve of each sex) 을 기준으로 자료를 상하로 분류하여 각각 조 숙군과 만숙군의 성장곡선을 추정하였다.

조숙군은 168 일령에 출하체중인 $110 \mathrm{~kg}$ 에 도 달하는 것으로 나타났다. 이에 반해 만숙군은
191일령에 도달하여 약 23일간의 차이를 보여 주고 있다. 똑같은 사육환경에서 이러한 성장 의 차이는 종돈의 유전적 개량에 의한 경제가 치의 제고 가능성을 보여주고 있다. 버크셔의 다른 경제형질의 특징을 제외하고라도 증체에 의한 다른 개량종 품종인 요크셔 랜드레이스와 경쟁이 가능한 것으로 사료된다. 특히 요크셔 랜드레이스 $90 \mathrm{~kg}$ 도달일령 각각 150 일(서, 1996), 151 일 $(\mathrm{Kim}, 2002)$ 과 각각 암퇘지의 경우 151.7 일과 154.1일 그리고 수퇘지의 경우 145.4 일과 146.1 일 (종축개량협회 2005) 비교할 때 전 두수 검정을 하면서 148 일을 나타낸 버크셔 품 종이 오히려 우수한 것으로 보여진다. 일반적 으로 개량종 품종들이 170 일에서 180 일령 사이 에 $110 \mathrm{~kg}$ 에 도달하는데 전체 군에서 178 일령 에 도달하는 것으로 추정되어 산육성에 있어 버크셔 품종이 다른 품종과 비교할 때 대등하 게 나타났다. 그림에서 나타나듯이 만숙군은 출하체중에 도달한 이후 전체 군 성장곡선에 접근하지만 조숙군은 이후에도 계속적인 성장 을 지속하여 365 일령에서 전체 돈군과 $8.9 \mathrm{~kg}$ 의 차이를 보이며 만숙군은 $2.9 \mathrm{~kg}$ 의 차이를 보이 고 있다.

성장속도를 측정하기 위해서는 $90 \mathrm{~kg}$ 도달일 령 또는 일당증체량을 이용하여 측정하고 이를 분석하여 종돈의 성장에 평가와 더불어 선발을 통하여 개량한다. 캐나다의 경우 일당증체량을 사용하며, 일당증체량은 개시체중 $30 \mathrm{~kg}$ 과 종료 체중 $90 \mathrm{~kg}$ 을 기준으로 보정하였으며 캐나다의 추정식(CCSI, 1997)은 다음과 같다.

Average daily gain $=($ weight/age $) \times 1.47 \cdots \cdots$

식에서 1.47 은 $30 \mathrm{~kg}$ 과 $90 \mathrm{~kg}$ 사이의 일당증 체량으로 환원하기 위한 종료체중만을 이용한 일당증체량(weight/age)에 의한 회귀 계수이다. 캐나다의 보정방법은 검정소 검정과 종료체중 만 이용하는 농장검정 자료의 통합을 위한 목 적이 있는 듯 하다. 그러나 역으로 검정소 검 
정자료의 종료 체중만을 이용한 일당 증체량을 농장검정자료와 통합한다면 일률적으로 적용되 는 1.47 의 상수는 의미가 없다. 국내에서 사용 되는 일당증체량도 같은 방법으로 사용한다(농 림부 등, 2004). 미국은 $250 \mathrm{lb}$ 정도 도달되었을 때 체중을 측정하며 정확히 $250 \mathrm{lb}$ 에 도달하는 일령을 통하여 성장률을 표시한다. 다음은 측 정 체중과 측정시 일령을 이용하여 $250 \mathrm{lb}$ 도달 일령을 추정하는 National Swine Improvement Federation(NSIF)의 추정식이다.

Adjusted days $=$ age $+[($ desired weight - weight $)$

$\times$ (age - a) /weight] .

식에서 $\mathrm{a}$ 의 값은 웅돈은 50 , 처녀돈은 40 이 다. 한국종축개량협회(KAIA; 2005)에서는 미국 의 방법을 도입하여 성별 구별하지 않고 $\mathrm{a}$ 의 값을 38로 사용하고 있다.

이 연구에서 버크셔 품종의 성장형질 추정을 위하여 계산된 체중의 Gompertz model 성장곡 선식은 다음과 같다.

$$
w_{t}=163.3 e^{-4.727 e^{-0.014 t}}
$$

for $\mathrm{t}=1,2,3 \cdot \cdots \mathrm{n}$

식에서 $w_{t}$ 는 $t$ 일령의 체중이다. (3)식에 근 거하여 $90 \mathrm{~kg}$ 도달일은 $t_{90}$ 일이라면, 이 일령은 (3)식을 보정계수 산출을 위한 식으로 사용하는 한 기준이 된다. $t_{90}$ 일령의 종료체중에 대한 보 정계수를 얻고자한다면 보정계수는 (3)식의 $w_{t}$ 로부터 다음과 같이 얻어진다.

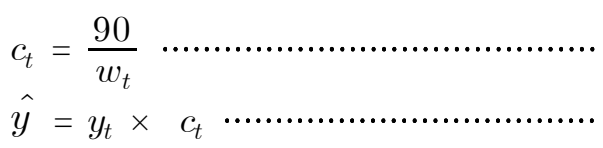

Daily gain $=\hat{y} / t_{90}$

식에서 $y_{t}$ 는 $\mathrm{t}$ 일령에 측정된 실측치이고, $\hat{y}$ 는 $t_{90}$ 일령으로 보정된 종료체중이다. 따라서 일당증체량은 간단히 $\hat{y}$ 를 $t_{90}$ 일로 나누어 주 면 얻어진다. 모든 개체의 종료체중이 $t_{90}$ 일령 으로 보정됨으로써 이론적으로 같은 일령을 기 준으로 한 종료체중의 직접비교 또는 일당증체 량의 비교가 가능해진다. $90 \mathrm{~kg}$ 도달일령의 추 정도 표준성장곡선의 $90 \mathrm{~kg}$ 도달기준인 $t_{90}$ 일령 을 부분적으로 이용하여야하며 그리하여 $90 \mathrm{~kg}$ 도달일령을 산출하는 식은 다음과 같이 얻어진 다.

$$
\hat{t}=t+\left(90-y_{t}\right) / \text { daily gain } \text { gat }_{90} \cdots \cdots \cdots \cdots(7)
$$

$$
\begin{aligned}
& \text { Daily gain }_{t \rightarrow t_{90}}= \\
& \left\{\begin{array}{l}
\left(w_{t+1}-90\right) \times y_{t} / w_{t}, \quad t-1<t_{90}<t \\
\left(90-w_{t-1}\right) \times y_{t} / w_{t}, \quad t \leqq t_{90}<t+1 \\
\left(90-w_{t}\right) /\left(t_{90}-t\right) \times y_{t} / w_{t}, \text { otherwise }
\end{array}\right.
\end{aligned}
$$

식(7)에서 $t$ 는 개체의 체중측정일령이며, $\hat{t}$ 는 추정된 개체의 $90 \mathrm{~kg}$ 도달일령이며 이는 $t$ 일령부터 $90 \mathrm{~kg}$ 에 도달하기 위하여 보정된 일 당증체량으로 도달할 수 있는 일령을 추가함으 로써 얻어진다. 보정된 개체의 일당증체량을 구하는 식(8)에서 $\left(90-w_{t}\right) /\left(t_{90}-t\right)$ 는 $t$ 일령부 터 $t_{90}$ 일령 또는 $t_{90}$ 일령의 표준화된 일당증체 량이며, 항상 양수이다. 이를 $\left(y_{t} / w_{t}\right)$ 로 곱하여 줌으로써 그 개체의 발육정도를 보정하여 그 구간의 일당 증체량을 계산한다.

(5)와 (6)의 식의 근거가 같은 일령을 기준으 로 했다면, (7)의 식은 같은 체중 즉 $90 \mathrm{~kg}$ 을 기 준으로 한다. 실제 일당증체량을 같은 일수를 적용하지 않는다면 Table 1에서 계산되어지는 생시부터 체중 측정 구간별로 일당증체량은 크 게 차이가 나는 것을 감안한다면 잘못된 일당 증체량의 예측이 되고, (7)의 식에서처럼 $90 \mathrm{~kg}$ 에 도달하기 직전직후의 일당증체량으로 경과 
되거나 경과되어야 할 일 수를 계산하지 않는 다면 일당증체량은 직전직후의 일당증체량 보 다 작거나 크기 때문에 $90 \mathrm{~kg}$ 도달일령의 편차 가 커질 수밖에 없다. 이러한 점에서 성장곡선 에 의한 추정법이 이론적으로 우수하다.

이러한 식들의 적용은 정확도의 개선을 가져 온다 하더라도 복잡한 계산과 과정을 거쳐 언 뜻 사용하기 어려워 보이는데, 요즈음 종돈농 장이나, 종돈개량기관에서 자료의 처리는 대부 분이 컴퓨터로 처리하기 때문에 이러한 식들을 쉽게 적용될 수 있다. 또한 한 농장 내에서 여 러 품종이 있을 경우와 암수 성별에도 각각의 성장곡선을 추정하여 적용할 수 있다. 품종간 의 성장률의 차이는 나타나지만(조 등, 2004), 캐나다나 미국의 방법에서는 품종간의 차이를 인정하지 않고 있다. 또한 고정된 목표 체중으 로부터 어느 정도 멀리 있는지 고려하지 않는 다. 이럴 경우 체중 측정시점에 따라 일당증체 량이나 $90 \mathrm{~kg}$ 도달일령의 산출은 부정확해 질 수 있다. Table 2에서는 일당증체량과 $90 \mathrm{~kg}$ 도 달일령에 대한 기존의 보정방법과 성장곡선에 의한 보정방법상의 예를 들어 보여주고 있다. 위의 표로 방법상의 실질적인 차이를 쉽게 보 여주지는 못하지만 돼지들의 순위에서 각 방법
들이 차이가 나타나는 것을 알 수 있다.

그림이 이러한 차이를 설명하는 데에는 용이 하여 Fig. 3과 4를 제시하였다. 그림에서 A,B, $\mathrm{G}$ 그리고 $\mathrm{H}$ 는 Table 2의 돼지 개체를 의미한 다. (3)식은 $t_{90}$ 을 148.4161 로 추정한다. 실선에 의한 148 일령의 종료체중은 캐나다의 추정방법 으로 성장곡선을 무시하고 일률적으로 생시부 터 종료체중 측정일까지 같은 속도로 성장했을 때의 성장률을 나타내어 138일령이나 148일령 에서도 똑같은 일당 증체량을 보여준다. 그러

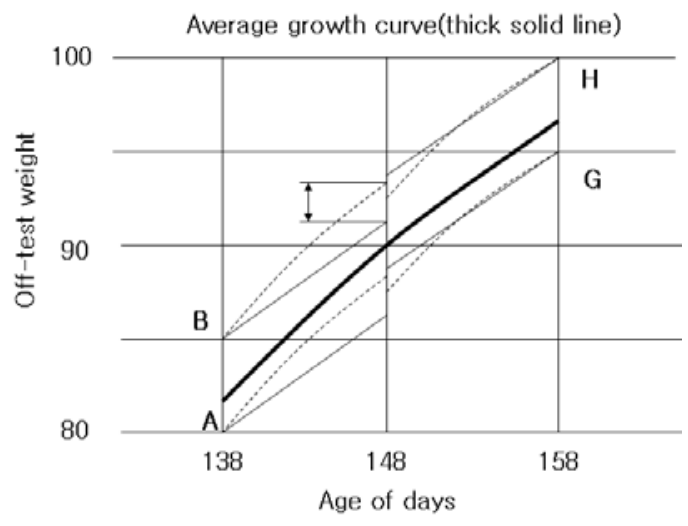

Fig. 3. Illustration of the difference in Canadian method (solid line) and growth curve method (dotted line).

Table 2. Comparison of examples by each method

\begin{tabular}{ccccccccccc}
\hline Pig & Age & Weight(kg) & DG $^{1)}$ & Rank & Days $^{2)}$ & Rank & DG $^{3)}$ & Rank & Days $^{3)}$ & Rank \\
\hline \hline A & 138 & 80 & 579.7 & 6 & 150.5 & 5 & 591.9 & 5 & 152.7 & 6 \\
B & 138 & 85 & 615.9 & 4 & 143.9 & 3 & 629.1 & 3 & 145.0 & 3 \\
C & 138 & 90 & 652.2 & 2 & 138.0 & 2 & 666.2 & 2 & 138.0 & 2 \\
D & 138 & 95 & 688.4 & 1 & 132.7 & 1 & 702.7 & 1 & 131.8 & 1 \\
E & 158 & 85 & 538.0 & 8 & 165.1 & 8 & 531.8 & 8 & 165.0 & 8 \\
F & 158 & 90 & 569.6 & 7 & 158.0 & 7 & 554.1 & 7 & 158.0 & 7 \\
G & 158 & 95 & 601.3 & 5 & 151.7 & 6 & 563.5 & 6 & 151.7 & 5 \\
H & 158 & 100 & 632.9 & 3 & 146.0 & 4 & 625.7 & 4 & 146.0 & 4 \\
\hline
\end{tabular}

For traits, DG and Days represent average daily gain(g) and days to $90 \mathrm{~kg}$ of body weight. Superscripts are estimates ${ }^{1)}$ by the Canadian adjustment method, ${ }^{2)}$ by the KAIA method and ${ }^{3)}$ by the growth curve. 


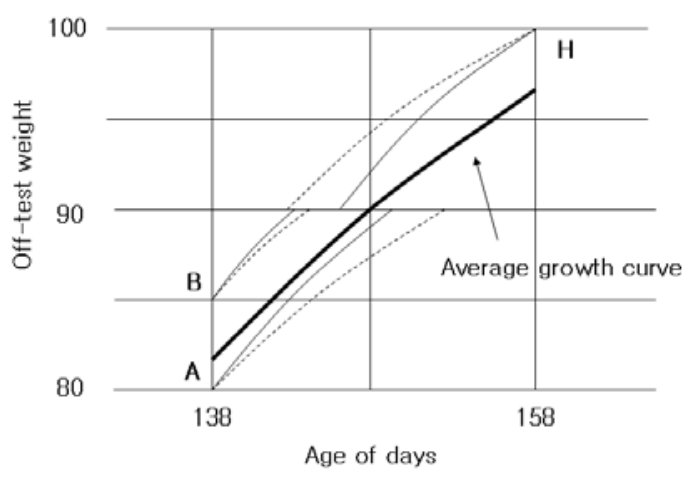

Fig. 4. Illustration of the difference in the U.S. method (solid line) and growth curve method (dotted line).

나 점선은 성장곡선에 따라 추정한 종료체중을 의미하여 138 일령 절대적인 일당 증체량과 148 일령의 보정된 종료체중에서의 일당증체량 값 은 차이가 있다. Fig. 3의 화살표는 캐나다의 방법과 성장곡선에 의한 방법에 의해서 나타나 는 누적된 일당증체량의 차이를 보여준다.

Table 2에서 NSIF를 원용한 한국종축개량협 회(KAIA)의 방법과 성장곡선에 의한 방법이 90 $\mathrm{kg}$ 도달일령의 순위에서 차이가 있음을 보여준 다. Fig. 4에서 나타나듯이 측정된 체중이 $90 \mathrm{~kg}$ 에서 멀어질수록 두 방법간의 차이가 커짐을 보여주고 있다. 특히 미국의 방법은 $90 \mathrm{~kg}$ 으로 부터 멀어질수록 평균 쪽으로 더 많이 쏠림으 로서 종료체중 측정일의 범위가 넓어지는 것에 대한 제한을 더 많이 받을 수밖에 없다.

Table 3은 성장곡선 추정에 이용한 자료로
분석하였으며 시기별로 측정된 체중, 일당증체 량 그리고 추정된 종료체중과의 상관계수를 보 여준다. 표에서 체중 측정일령을 감안하여 검 정기간 내에 한정하여 추정되어진 것이 일당증 체량(daily gain)이지만 검정개시와 종료시점의 일령에 따라 보정되지 않은 상태이다. 보정된 체중(adj. off-test)은 개체의 성장곡선에 의해 $t_{90}$ 에 맞추었기 때문에 일당증체량과 같은 효 과를 나타낸다고 말할 수 있다. 일반적으로 생 시, 이유시, 개시 및 종료체중들과의 양의 상관 관계가 형성되어 생시체중이 우수한 개체가 지 속적으로 잘 크며 종료체중이 우수한 것을 나 타낸다. 표에서 보정된 종료체중이 Off-test나 Daily gain ${ }^{1}$ 보다 생시체중, 이유시 체중 그리고 검정개시 체중과의 상관관계가 높은 것은 특기 할만하다.

Table 4는 성장곡선 추정시 포함되지 않았던 자료를 포함한 3,100두의 자료로부터 얻은 결 과이다. 생시체중도 성장형질중의 하나이며, 어 느 정도는 일당증체량이나 $90 \mathrm{~kg}$ 도달일령과 상관이 있을 것으로 추측된다. 두 형질과의 상 관계수가 일관되게 성장곡선 추정법이 각각 음 과 양으로 높게 나타나고 특히 유전상관과 일 당 증체량에서는 차이가 크다. 이를 정확도의 기준으로 삼을 수는 없지만 생시체중은 한 개 체에서 시기적으로 다르게 측정한 형질이고 외 적요인에 적게 영향 받는 형질이므로, 상관이 높은 쪽의 추정방법이 정확하다고 하더라도 무 리가 없다.

Table 3. Correlations among periodically measured pig weights and daily gain

\begin{tabular}{cccccc}
\hline & Weaning & On-test & Off-test & Daily gain $^{1)}$ & Adj. off-test $^{2)}$ \\
\hline \hline Birth & 0.43 & 0.37 & 0.19 & 0.18 & 0.32 \\
Weaning & & 0.53 & 0.21 & 0.19 & 0.36 \\
On-test & & & 0.42 & 0.18 & 0.54 \\
Off-test & & & 0.58 & 0.68 \\
\hline
\end{tabular}

Daily gain ${ }^{1)}=$ (off-test weight - on-test weight) / days of test period and Adj. off-test ${ }^{2)}$ represents off-test weight adjusted by equation (5). 
Table 4. Correlations of birth weight with average daily gain and days to $90 \mathrm{~kg}$ according to estimation methods

\begin{tabular}{cccccc}
\hline \multirow{2}{*}{ Correlation } & \multicolumn{2}{c}{ Conventional $^{1)}$} & & \multicolumn{2}{c}{ Growth Curve } \\
\cline { 2 - 3 } \cline { 5 - 6 } & Days to 90kg & Daily gain & & Days to 90kg & Daily gain \\
\hline \hline Phenotypic & -0.00 & 0.03 & & -0.02 & 0.10 \\
Genotypic & -0.00 & 0.06 & & -0.04 & 0.22 \\
\hline
\end{tabular}

Conventional $^{1)}$ represents the Canadian and KAIA methods.

어느 방법이 더욱 정확한 가의 차이는 모든 개체의 체중을 직접 측정하지 않고는 알 수 없 기 때문에 어느 방법이 더욱 논리적인가의 귀 결이 될 수밖에 없다. 성장곡선에 의한 추정방 법은 일당증체량과 $90 \mathrm{~kg}$ 도달일령에서 공통적 으로 한 가지의 기준을 가지고 있다. 일당증체 량의 경우 똑같은 일령에 비교될 수 있도록 성 장곡선으로 확장(projection) 하였고, $90 \mathrm{~kg}$ 도달 일령의 경우 측정일까지의 성장곡선상의 성장 속도로 개체가 측정된 체중부터 $90 \mathrm{~kg}$ 성장하 는데 도달할 수 있는 일수를 계산하였다. 이러 한 점에서 성장곡선에 의한 일당증체량과 90 $\mathrm{kg}$ 도달일령이 서로 역으로 계산되지 않는다. 이에 대해 문제를 제기할 수 있으나 같은 성장 곡선을 사용하였다 하더라도 접근방식이 다르 기 때문에 캐나다의 방법과 일당증체량을, NSIF 방법과 $90 \mathrm{~kg}$ 도달일령을 비교하여야 한다.

\section{IV. 요 약}

돼지의 중요한 경제형질인 성장형질은 검정 기간동안의 증체량이나 특정한 체중에 도달하 는 일수를 측정한다. 그러나 성장형질은 개체 의 능력외의 다른 요인에 의해서도 영향을 받 는다. 유전능력 평가를 위해서는 합리적인 측 정치를 이용하여 불필요한 오류를 줄여야 한 다. 이러한 요인에 의한 성장률의 차이를 줄이 기 위하여 경남첨단양돈연구소의 경남흑돈 (Berkshire) 1,576두의 자료를 가지고 성장곡선 을 추정하여 성장곡선에 의해 일당증체량과 90 $\mathrm{kg}$ 도달일령을 각각 추정하였다. 기존의 방법 들과 정확도를 직접적으로 비교할 수 없으나 추정하는 방법론에 있어서 더 정교하여졌다. 이론적 우수성은 일당 증체량에서는 성장곡선 상의 같은 연령을 비교하고, $90 \mathrm{~kg}$ 도달일령에 서는 종료체중 측정일에서 $90 \mathrm{~kg}$ 도달일까지의 일수를 개체의 성장곡선상의 일 증체량으로 계 산하는 데에 있다. 또한 컴퓨터를 활용한다면 품종이나 성과 같은 요인들에 대해서도 이 추 정방법을 쉽게 각각 적용할 수 있다.

\section{$\mathrm{V}$. 인 용 문 헌}

1. 농림부. 축산기술연구소. 2004. 가축개량관련자료

2. 서강석. 1996. 다형질 애니멀 모델에 의한 돼지 경제형질의 유전 모수, 유종가 및 유전적 변화 추세의 추정에 관한 연구. 서울대학교 박사학위 논문.

3. 조영민, 최봉환, 김태헌, 이지웅, 이지의, 오성종, 정일정. 2004. 재래돼지와 랜드레이스 교잡종의 개체별 성장곡선 추정 및 육질 형질과의 상관관 계 추정에 관한 연구. 동물자원과학회지 46(4): 503.

4. 한국종축개량협회. 2005. 농장검정보고서 http: //www.aiak.or.kr

5. CCSI. 1997. Estimating Average Daily Gain from Weight and Age http://www.ccsi.ca

6. Kim, J. I. 2002. Animal model estimation of genetic parameters for direct genetic effect for 
productive and reproductive traits in swine. Ph. D. Thesis. Seoul National University.

7. NSIF. 2002. Swine Improvement Program Guidelines http://www.nsif.com/

8. SAS. 2001. SAS/STAT SAS Institute., Cary, NC, USA.
9. USDA. 2006. MTGSAM and MTDFREML http: //www.aipl.arsusda.gov/curtvt/

10. Winsor, C. R. 1932. The Gompertz curve as growth curve. Proc. Natl. Acad. Sci. 18:1.

(접수일자 : 2007. 2. 22. / 채택일자 : 2007. 4. 20.) 